\title{
LA CAJA DE MADRID EN EL SIGLO XIX: ¿ACTIVIDAD ASISTENCIAL O FINANCIERA?
}

\author{
MANUEL TITOS MARTINEZ \\ Universidad de Granada
}

Hace ciento cincuenta años, el 17 de febrero de 1839 , se inauguraba la primera Caja de Ahorros de España, la Caja de Madrid. Como entidad independiente, la Caja aportaría sus recursos al funcionamiento de una institución madrileña, el Monte de Piedad, nacido a comienzos del siglo xvill, con la que terminaría fusionándose en 1869.

La vinculación que en la historia de España ha existido entre las Cajas de Ahorros y los Montes de Piedad, ha hecho que a menudo se atribuya a éstas un carácter benéfico o asistencial, excluyéndolas hasta épocas recientes de los circuitos financieros y de una consideración económica de su actividad. Naturalmente que esta consideración no está exenta de razones objetivas. Muchas Cajas de Ahorros consumieron sus recursos en la concesión de préstamos con garantía prendaria a través de los Montes de Piedad, contribuyendo a garantizar la subsistencia de una serie de capas sociales bastante desprotegidas.

No es ése el caso de la Caja de Madrid, donde el éxito en la captación de ahorro le llevó a buscar pronto cauces de inversión distintos, de consideración económica mucho más importante de lo que se pudiera suponer, hasta el punto que sus operaciones más típicas, los empeños, constituyeron una parte mínima de sus activos, compuestos preferentemente por préstamos con garantía de valores, que no tienen, en absoluto ese carácter asistencial supuesto. ¿Cómo valorar el hecho, por ejemplo, de que la Caja de Madrid tenga en 1885 unas inversiones cifradas en 44,8 millones de pesetas, mientras que los mismos conceptos para el Banco de Bilbao sumen 23,7 para el de Barcelona 28,4 y para el de Castilla 15,5 millones de pesetas?

Pero es que, en la misma fecha, los depósitos de la Caja de Madrid sumaban 43,1 millones de pesetas, tres menos que los que había en el Banco de Barcelona, pero bastante más de lo que representaban en el Banco de Bilbao, 24 millones, o en el de Castilla, 5,9. Y no es que sea necesario revisar la historia en su totalidad. Que esa función asistencial existió, no solamente es indudable, sino que, objetivamente, fue en sus comienzos la 
base y fundamento de la existencia de las Cajas de Ahorros, incluso de la de Madrid. Pero junto a ese papel tradicional, el estudio de la Caja de Madrid nos abre perspectivas distintas para analizar el fenómeno del ahorro en España, atribuyendo a la intermediación realizada por las Cajas una dimensión económica que hasta la década de los años sesenta de este siglo, muchos se negaban a reconocer.

El cumplimiento de esta función económica es el objetivo que, tomando como referencia la celebración del 150 aniversario de la fundación de la Caja de Ahorros de Madrid, pretende brevemente desarrollar este artículo.

\section{El marco legislativo del aborro español en el siglo XIX}

La primera norma legislativa que en la jurisprudencia española trata de las Cajas de Ahorros es la Real Orden de 3 de abril de 1835, en la que, como consecuencia de la campaña desplegada por Mesonero Romanos en la prensa, la acción de la Sociedad Económica Matritense de Amigos del País y la intervención del Marqués de Pontejos, el Gobierno va a dar su apoyo oficial a la creación de Cajas de Ahorros en España. Lo cierto es que la Orden no pasa de ser una llamada de atención a los Gobernadores Civiles para que aúnen recursos que permitan poner en funcionamiento estas entidades, pero de la misma interesa resaltar dos aspectos. En primer lugar, la intención ya manifiesta de utilizar el ahorro popular para la financiación pública: «llegará un día en que, restablecido enteramente el crédito del Estado, sean los fondos públicos el asilo seguro y ventajoso de los ahorros del pobre». En segundo lugar, la asunción por parte del Gobierno de una función directamente promotora de Cajas de Ahorros.

El primer fruto de la Real Orden será la constitución de la Caja de Ahorros de Madrid, aprobada mediante Real Decreto de 25 de octubre de 1838. La instrucción para su funcionamiento fue aprobada el 1 de febrero de 1839 y su Reglamento mediante Real Orden de 17 de julio de 1839. Pero poco antes de esta última fecha y mediante Real Orden de 17 de abril de 1839, nuevamente el Gobierno va a hacer una llamada de atención a las autoridades provinciales encaminada al fomento de las Cajas, si querían «merecer el agrado de Su Magestad». La Orden, fruto de la preocupación del Gobierno porque proliferaran estas instituciones, va a tener efectos inmediatos, con la creación de una serie de entidades distribuidas por todo el país: Granada (1839), Sagunto (1841), Sevilla, Santander, La Coruña y Valencia (1842), Barcelona (1844), Burgos y Cádiz (1845) y Vitoria (1850).

Catorce años más tarde, con esta experiencia y mediante el Real Decreto de 29 de junio de 1853 , se va a llevar a cabo el primer intento de regular 
de manera sistemática y completa las Cajas de Ahorro, con una innegable pretensión uniformadora'. Del Decreto citado son de destacar algunas notas críticas al margen de su contenido concreto. En primer lugar, plantea por primera vez la necesidad de que institucionalmente Montes de Piedad y Cajas de Ahorros vayan unidos, cosa que hasta ahora no sucedía, si bien las autoridades nunca dejaron de recomendarlo en los textos anteriores. En segundo lugar, si hasta ahora la norma básica de cada entidad eran sus propios Estatutos y para la redacción de los mismos existía una libertad plena, el Real Decreto incorpora un matiz unificador para todas las Cajas, que deberán tomar como modelo el Reglamento de la de Madrid. Por otra parte, el texto regula de una manera minuciosa el funcionamiento y la organización de las entidades afectadas, la asignación de sus recursos y de sus excedentes, la constitución de sus fondos de reserva... Por otro lado. vincula las Cajas a los poderes provinciales o locales, determinando que serán los Gobernadores y los Alcaldes quienes presidirán respectivamente las Juntas en capitales y pueblos. Por último, el artículo 36 del Decreto establece que las Cajas de Ahorros tendrán el carácter de establecimientos municipales de beneficencia, lo que les atribuye automáticamente un carácter público, ya que la Ley de Beneficencia de 20 de junio de 1840 señalaba expresamente que «los establecimientos de beneficencia son públicos».

A partir de 1853 se enfrentarán de manera casi permanente dos concepciones en relación con las Cajas de Ahorros. La de los poderes públicos, por un lado, encaminada a conseguir una uniformización del particularismo estatutario de las Cajas y a poner sus recursos al servicio de su política cconómica. Frente a ésta, la actitud casi permanente de buena parte de las Cajas en defensa de su autonomía estatutaria y de una completa libertad de acción y de organización. La primera batalla - ha dicho González Morenoserá ganada por las Cajas de Ahorro ${ }^{2}$. Así, cuando el Gobierno intentó vincular los fondos de las Cajas a la financiación de la Caja General de Depósitos y, en consecuencia, a la Deuda Pública, la alarma cundió entre los impositores. Se produjo entonces una retirada masiva de depósitos en algunas entidades y el Gobierno tuvo que dejar en suspenso la aplicación del Decreto de 1853 durante mucho tiempo y mediante la Real Orden de 2 de julio y de 1 de agosto del mismo año se prorrogará indefinidamente el plazo de dos meses que daba el Real Decreto para reformar los Estatutos de las Cajas existentes, dejando al celo y prudencia de los Gobernadores y Juntas Directivas el activar en todo lo posible la reforma de los Reglamentos de las Cajas para ponerlos en armonía con el Decreto de 1853. Las Cajas siguieron rigiéndose,

\footnotetext{
' Martín-Retortillo Baquer (1975), p. 333.

2 González Moreno (1983), p. 53.
} 
en consecuencia, por sus propios Estatutos y Reglamentos. Ninguna de las existentes transformó los mismos de acuerdo con los imperativos del Decreto y ninguna de las que se crearon a partir de entonces basó la redacción de sus normas rectoras en las prescripciones de la citada norma legal, con lo que el particularismo estatutario seguiría manifestándose como la norma fundamental durante todo el siglo xIx.

A los veintiséis años exactamente de que el Gobierno llevase a cabo este fracasado intento de reforma, se va a producir otro texto, esta vez en forma de Ley, promulgada el 29 de junio de 1880 , que va a posibilitar la creación de la mayor parte de las Cajas de Ahorros hoy existentes en España, pero desapareciendo ya totalmente las pretensiones uniformistas de 1853 , si bien el Gobierno, aunque sin dar normas para su confección, se reservaba el derecho de aprobar los Estatutos de cada entidad. El Gobierno se compromete mediante la misma a promover la instalación de Cajas de Ahorros y Montes de Piedad en todas las capitales de provincia y poblaciones más importantes donde aún no existiesen. Se procuraría que Cajas y Montes se instalaran conjuntamente para hacer más fácil su funcionamiento. De igual modo y siguiendo en la línea de fomento del ahorro el Gobierno promovería también el establecimiento de Cajas Escolares en escuelas e institutos. Todos los establecimientos de este tipo serían considerados como instituciones de beneficencia y se les concederían, finalmente, una serie de exenciones fiscales de interés.

La configuración de las Cajas como instituciones de beneficencia justifica plenamente su dependencia del Ministerio de la Gobernación, desapareciendo toda vinculación con el de Hacienda y con el ejercicio del protectorado, por una parte, y el derecho que el artículo primero de la Ley atribuye al Gobierno para examinar y aprobar los Reglamentos o Estatutos de cada institución «ínterin no aconsejen la práctica y el estudio del asunto una organización uniforme o general para estos importantes servicios»; se renuncia por ahora a las pretensiones intervencionistas y homogeneizadoras que presidieron el Real Decreto de 1853 y se reconoce el respeto por el particularismo de cada Caja, cuyos Estatutos serán objeto de estudio y aprobación de manera completamente individualizada.

Su vinculación preferente a las instituciones de beneficencia y el reconocimiento del particularismo de las Cajas se va a mantener vigente durante cuarenta y seis años. La siguiente norma legislativa que afectará a las Cajas de Ahorros será el Decreto de 9 de abril de 1926 emitido ahora por el Ministerio de Trabajo, Comercio e Industria y con él, al modificar la dependencia de las Cajas y señalarles un nuevo Ministerio protector, se estarán demandando de ellas nuevas funciones y marcándoles nuevos objetivos. 
¿Cómo evolucionó el número de Cajas de Ahorros en España al amparo de esta normativa? Desde que en 1839 se inauguró la Caja de Ahorros de Madrid hasta 1900, fueron 65 las Cajas de Ahorros fundadas en España, de las que 18 lo fueron durante el reinado de Isabel II, ninguna durante el Sexenio Revolucionario y las 47 restantes a partir de 1875 , durante la Restauración. De aquellas 65 Cajas fundadas en el siglo xix, únicamente diez han desaparecido en el transcurso del tiempo; 34 subsisten actualmente con nombres similares o idénticos a los fundacionales y las 21 restantes han sido objeto de procesos de fusión y cambios de denominación, por lo que se puede afirmar que, de una u otra forma, aún subsisten. Todo ello da una idea bastante precisa de la estabilidad del sector.

Desde el punto de vista de la distribución regional, la mayor abundancia de Cajas de Ahorros al finalizar el siglo XIX correspondía a Cataluña y Valencia con 14 Cajas en cada una de ellas. En Cataluña, de las 14 Cajas fundadas se mantienen todas ellas, en tanto que en Valencia han sido 15 las fundaciones, pero una primitiva Caja de Ahorros de Valencia sólo logró mantenerse de 1842 a 1867 . La siguiente región en número de Cajas será Andalucía, en donde hubo 11 fundaciones, de las que cinco tuvieron que liquidar (Granada, Cádiz, Málaga, Jaén y Linares); aun así, a finales de siglo se mantenían las Cajas de Sevilla, Jerez, Cádiz, Córdoba, Granada y Almería. Con cinco entidades cada una encontramos a Castilla-León y Galicia. En la primera ha habido siete fundaciones y dos liquidaciones (Valladolid y Burgos) y en la segunda ha habido seis fundaciones y una liquidación (La Coruña, 1842-1861). En la región Vasco-Navarra perviven las cuatro entidades fundadas a lo largo del XIX, lo mismo que sucede con las tres entidades fundadas en Aragón. Por último, con una sola entidad, encontramos a Madrid, Asturias, Extremadura y Santander.

\section{Los orígenes del Monte de Piedad y de la Caja de Aborros de Madrid}

La creación del Monte de Piedad será obra del sacerdote Francisco Piquer y Rudilla, capellán de las Descalzas Reales de Madrid, movido por su deseo de socorrer a los pobres. Con frecuencia se ha repetido lo que simbólicamente pudiéramos considerar como el acto fundacional del Monte de Piedad: el 3 de diciembre de 1702 reunió Francisco Piquer en su habitación en el Hospital de la Misericordia a sus parientes y amigos y tomando una «cajita de ánimas» les dijo: «Sean Vms. thestigos de que este real de plata que echo en esta Caja, a de ser el principio y fundamento de un Monte de Piedad que Dios á de fundar para sufragio de las ánimas y socorro de los vivos.» 
A la vez que iniciaba la colecta de fondos para llevar a cabo la fundación, inició Piquer la confección del Reglamento del Monte de Piedad con el asesoramiento de clérigos y letrados de la Corte, que en 1709 pudo finalmente presentar al cardenal Portocarrero, arzobispo de Toledo, cuyo Consejo de Gobierno terminó finalmente por aprobarlo.

Surgió sin embargo un importante conflicto de competencias. El Consejo de Toledo acordó que el Monte de Piedad tendría que sujetarse a la visita (inspección) eclesiástica. Pero de acuerdo con los propios Estatutos el Monte de Piedad habría de pasar a depender del Patronato Real, al haberse erigido en el Convento de las Descalzas, sometido a tal jurisdicción. Por otra parte, el control eclesiástico podía ejercerse por los miembros de la Junta General del Monte en la que figuraban dos eclesiásticos. Los amigos del Padre Piquer, encabezados por el conde de la Estrella, le aconsejaron la iniciación de los trámites para la incorporación del Monte al Patronato Real. Para ello, había que hacer una cesión al Rey de todos los efectos, bienes y capital del Monte, lo que requería a su vez el consentimiento de todos los que ya habían aportado fondos para su fundación. En estos trámites consumió Piquer los años 1709 a 1711, enviando en esta última fecha a Felipe $V$ un memorial y los estatutos de la entidad. El 9 de mayo de 1711 remitió el Rey los Estatutos a la Cámara de Castilla para la elaboración del informe correspondiente, que fue emitido de forma favorable el 13 de enero de 1712. El 18 de enero de 1713 delegó el Rey en Pedro de Larreátegui la firma de escritura de cesión del Monte de Piedad al Patronato Real, que se firmó el 12 de febrero siguiente. Sin embargo, hasta el 10 de junio de 1718 no se expediría la Real Carta de Privilegio de Fundación del Monte de Piedad de Madrid, con la inclusión y la aprobación de sus Estatutos ${ }^{3}$.

Los medios que ha utilizado Piquer para hacerse de un capital fundacional y los que va a utilizar en lo sucesivo para incrementarlo serán los siguientes: en primer lugar, las limosnas particulares, que a su vez derivan de varias procedencias: las rentas y mercedes reales de Indias (donativos, donaciones, rentas de obispados vacantes, etc.), los legados y herencias de particulares, las limosnas que voluntariamente dejaban para incremento del capital del Monte quienes acudían a llevar a cabo alguna operación de empeño, las cajas de ánimas domiciliarias y la mesa petitoria instalada en el claustro de las Descalzas en los días de novenario; en segundo lugar, el Monte pucde disponer para la realización de sus operaciones de los depósitos de fondos sin interés que le prestan determinadas personas, desde 1711 , y que permiten incrementar sensiblemente su operatoria; finalmente, Francisco Piquer idea cualquier otro procedimiento para obtener fondos, como fue la

\footnotetext{
${ }^{3}$ López Yepes (1973), pp. 73-84.
} 
edición y venta de las obras completas de Fray Luis de Granada, de las que se imprimieron 800 ejemplares y se vendieron a 180 reales cada uno de ellos. Cuando en 1739 muere Piquer, el capital propio del Monte de Piedad asciende a 1.415 .925 reales.

Cien años más habrá de vivir el Monte de Piedad de Madrid financiándose por este procedimiento, hasta que la difusión del nuevo espíritu y los nuevos hábitos del liberalismo obliguen a buscar otras fuentes de financiación a través de la creación de una Caja de Ahorros. En 1834 la Sociedad Económica Matritense de Amigos del País convocó un concurso para premiar una obra sobre la fundación de una Caja de Ahorros, que fue ganado por Francisco Quevedo y San Cristóbal. El mismo año Ramón de Mesonero Romanos realizaba una llamada encaminada al mismo objetivo en su Manual de Madrid, y más tarde, mediante cuatro artículos publicados entre 1835 y 1838 en el Diario de Avisos. Fue entonces cuando se puso en contacto con el marqués de Pontejos, Gobernador de Madrid, iniciando juntos los trabajos que conducirían a la fundación de la entidad. Desarrollado el proyecto y con el dictamen favorable de la Sociedad Económica Matritense, Pontejos fue el encargado de llevar a cabo la gestión gubernamental, consiguiendo su aprobación mediante el Real Decreto de 25 de octubre de 1838 y aunque no podemos entrar aquí en esta cuestión, es evidente que con la fundación de la Caja de Ahorros no solamente se pretende buscar un procedimiento de financiación para el Monte de Piedad. Ello queda claro en el preámbulo del mismo Decreto fundacional, en el que se afirma:

«Persuadida por cuanto me habéis expuesto, de lo vonveniente que sería establecer en Madrid una Caja de Ahorros en la que puedan las clases menos acomodadas depositar sucesivamente cortas cantidades, percibiendo réditos, con facultad de retirarlas siempre que les convenga; deseosa de mejorar la suerte y las costumbres de estas clases tan dignas de mi maternal solicitud, estimulando su laboriosidad, economía y previsión, he venido en decretar...»

Pontejos fue nombrado director primero de la Caja y se dedicó con firmeza a poner en marcha la entidad. El 1 de febrero se publicó una instrucción encaminada a dar a conocer la nueva institución y el 17 de febrero de 1839 tuvo lugar su inauguración. El 24 de febrero tenía lugar la firma de la escritura pública entre el Monte de Piedad y la Caja de Ahorros, que establecía un peculiar sistema de colaboración entre ambas entidades.

En efecto, la prcocupación respecto a las inversiones de los capitales que pudieran ingresarse en la Caja y por la disminución de los donativos que 
se estaba produciendo en el Monte de Piedad, llevó a los promotores y a las autoridades a concebir la Caja como un complemento del Monte de Piedad, pero manteniendo totalmente separadas ambas entidades, que tienen junta rectora y órganos directivos totalmente distintos. La Caja tiene, sin embargo, la obligación de entregar al Monte de Piedad todos los fondos que en ella depositen sus clientes; su único activo lo constituirán, en consecuencia, los créditos contra el Monte de Piedad, quien tiene que abonar a la Caja un interés anual de 5 por 100; de dicho importe, la Caja revierte a sus clientes un 4 por 100, quedando el 1 por 100 restante para gastos de administración e incremento de su capital propio. Por su parte el Monte de Piedad ve ampliamente resuelto su problema de tesorería, pero tendrá desde entonces que imponer a sus operaciones una tasa de interés obligatoria, convirtiéndose los empeños en una operación mercantil, cuando hasta ahora eran una operación netamente benéfica. Este peculiar flujo de fondos y separación institucional entre el Monte y la Caja se mantendrá hasta la fusión de ambas entidades que se producirá el 22 de abril de 1869.

\section{Los comienzos del aborro en la Caja de Madrid (1839-1868)}

En el cuadro 1 se contiene la evolución del número de cuentas y del saldo de ahorro de la Caja de Madrid desde su fundación, el 17 de febrero de 1839 hasta finales del siglo xix. Fijándonos ahora en la etapa que aquí nos interesa, la que se cierra en 1868 , podemos observar cómo el número de clientes ha llegado a estar situado en 14.794 en 1863 y su saldo de ahorro en 6,98 millones de pesetas el año anterior, aunque el período ahora considerado se cierre con 9.686 clientes y 4,94 millones de pesetas en depósitos. Esto demuestra ya que no existe una evolución uniforme y que el ahorro popular careció de esa presumible estabilidad para verse también afectado por distintas situaciones críticas, como sucede en 1848,1853 y, sobre todo, a partir de 1862.

En líneas generales podemos afirmar que el principal y más constante prob'ema de este período va a ser la dificultad del Monte de Piedad para poder colocar en préstamos los caudales que recibe de la Caja de Ahorros. El éxito de la Caja desbordaba todas las previsiones. Pero es que, además, la competencia a la que se veía sometido el Monte por parte de las casas de empeño y prestamistas particulares reducía sus posibilidades operativas. Y no es, naturalmente, que dichas casas prestasen a menos tasa que el Monte. Como ha quedado algunas veces de manifiesto, el problema radicaba en la rapidez de las operaciones, el mayor sigilo con que se realizaban y la posibilidad de entregar en prenda cualquier tipo de bien, frente a criterios algunas veces más 
restrictivos en los Montes de Piedad ${ }^{4}$. Analizando los censos de contribución industrial y de comercio encontramos que en 1856 operaban en Madrid 89 prestamistas; en 1870,83 ; en 1872,86 , y en 1973 , nada menos que $203^{5}$. Por otra parte, y en relación con el nivel de competencia de estos prestamistas entre sí y con el Monte de Piedad, nos encontramos con que en el Diario Oficial de Avisos de Madrid aparecen publicados entre 1856 y 1873, 9.353

\section{CUADRO 1}

Evolución del número de impositores, saldo de aborro $y$ fondo de reserva, 1839-1900

(En pesetas)

\begin{tabular}{|c|c|c|c|c|c|c|}
\hline Años & $\begin{array}{c}\text { Número } \\
\text { de } \\
\text { impositores }\end{array}$ & $\begin{array}{l}\text { Saldo } \\
\text { de } \\
\text { aborro }\end{array}$ & $\begin{array}{c}\text { Saldo } \\
\text { medio } \\
\text { por cuenta }\end{array}$ & $\begin{array}{c}\text { Beneficios } \\
\text { anuales }\end{array}$ & $\begin{array}{c}\text { Fondo } \\
\text { de } \\
\text { reserva }\end{array}$ & $\begin{array}{c}\text { Reservas } \\
\text { sobre } \\
\text { aborro }\end{array}$ \\
\hline 1839 & 1.081 & $314.245,58$ & 290 & & & \\
\hline 1840 & 1.545 & $722.762,21$ & 468 & $3.375,76$ & $3.375,76$ & 0,5 \\
\hline 1841 & 2.001 & $991.283,41$ & 491 & $5.053,23$ & $8.428,99$ & 0,9 \\
\hline 1842 & 2.216 & $997.236,82$ & 450 & $6.986,01$ & $15.415,00$ & 1,5 \\
\hline 1843 & 2.373 & 1.094 .165 .64 & 461 & $6.299,01$ & $21.714,01$ & 2 \\
\hline 1844 & 2.947 & $1.324 .514,62$ & 450 & $8.420,30$ & $30.134,31$ & 2 \\
\hline 1845 & 3.428 & $1.626 .989,35$ & 475 & $8.250,18$ & $38.384,49$ & 2 \\
\hline 1846 & 3.911 & $1.889 .159,40$ & 483 & $10.469,28$ & $48.853,77$ & 3 \\
\hline 1847 & 4.901 & $2.105 .800,63$ & 513 & 13.231 .51 & $62.085,28$ & 3 \\
\hline 1848 & 3.335 & $1.849 .871,79$ & 555 & $12.927,19$ & $75.012,47$ & 4 \\
\hline 1849 & 3.607 & $2.263 .975,72$ & 628 & $11.162,78$ & $86.175,25$ & 4 \\
\hline 1850 & 4.679 & $2.709 .365,98$ & 579 & $17.527,25$ & $103.702,50$ & 4 \\
\hline 1851 & 5.573 & $3.124 .423,65$ & 561 & $22.581,21$ & $126.283,71$ & 4 \\
\hline 1852 & 6.566 & $3.558 .578,79$ & 542 & $14.753,06$ & $141.036,77$ & 4 \\
\hline 1853 & 5.444 & $2.990 .958,58$ & 550 & $17.653,95$ & $158.690,72$ & 5 \\
\hline 1854 & 5.557 & $3.074 .165,54$ & 563 & $15.713,26$ & $174.403,98$ & 6 \\
\hline 1855 & 6.016 & $3.317 .553,39$ & 552 & $18.129,74$ & $192.533,72$ & 6 \\
\hline 1856 & 7.429 & $3.815 .060,01$ & 514 & $19.578,97$ & $212.112,69$ & 6 \\
\hline 1857 & 8.860 & $4.316 .367,25$ & 487 & $21.425,56$ & $233.538,25$ & 5 \\
\hline 1858 & 10.216 & $4.998 .140,81$ & 488 & $29.613,81$ & $263.152,06$ & 5 \\
\hline 1859 & 11.577 & $5.613 .784,65$ & 485 & $35.431,69$ & $298.583,75$ & 5 \\
\hline 1860 & 12.814 & $6.259 .755,87$ & 489 & $39.864,82$ & $338.448,57$ & 5 \\
\hline 1861 & 13.846 & $6.658 .137,46$ & 481 & $44.456,09$ & $382.904,66$ & 6 \\
\hline 1862 & 14.782 & $6.988 .092,20$ & 473 & $42.654,44$ & $425.559,10$ & 6 \\
\hline 1863 & 14.974 & $6.882 .931,94$ & 460 & $47.943,18$ & $473.502,28$ & 7 \\
\hline 1864 & 14.883 & $6.867 .986,46$ & 463 & $48.672,26$ & $522.174,54$ & 8 \\
\hline $186^{\circ}$ & 13.793 & $6.193 .014,26$ & 449 & $48.242,62$ & $570.417,26$ & 9 \\
\hline 1866 & 12.354 & $5.806 .879,32$ & 470 & $45.347,86$ & $615.765,02$ & 11 \\
\hline 1867 & 11.564 & $5.866 .482,33$ & 490 & $45.670,17$ & $661.435,19$ & 12 \\
\hline 1868 & 9.686 & $4.914 .473,61$ & 511 & $48.625,84$ & $710.061,03$ & 14 \\
\hline
\end{tabular}

4 Puede verse una ampliación de esta cuestión en Titos Martínez (1978), tomo I, ca pítulo II: «La usura y las casas de empeño granadinas en el siglo xix».

Montero Carnerero (1983). 


\section{CUADRO 1 (Continuación)}

Evolución del número de impositores, saldo de aborro $y$ fondo de reserva, 1839-1900

(En pesetas)

\begin{tabular}{|c|c|c|c|c|c|c|}
\hline$A \tilde{n} o s$ & $\begin{array}{c}\text { Número } \\
\text { de } \\
\text { impositores }\end{array}$ & $\begin{array}{l}\text { Saldo } \\
\text { de } \\
\text { aborro }\end{array}$ & $\begin{array}{c}\text { Saldo } \\
\text { medio } \\
\text { por cuenta }\end{array}$ & $\begin{array}{c}\text { Beneficios } \\
\text { anuales }\end{array}$ & $\begin{array}{l}\text { Fondo } \\
\text { de } \\
\text { reserva }\end{array}$ & $\begin{array}{c}\text { Reservas } \\
\text { sobre } \\
\text { aborro }\end{array}$ \\
\hline 1869 & 5.151 & $2.429 .164,59$ & 472 & $106.178,04$ & $2.855 .957,65$ & 118 \\
\hline 1870 & 6.089 & $3.204 .507,00$ & 526 & $113.957,50$ & $2.971 .052,65$ & 93 \\
\hline 1871 & 8.318 & $4.657 .838,72$ & 560 & $62,060,00$ & $3.033 .112,65$ & 65 \\
\hline 1872 & 10.269 & $6.385 .905,86$ & 622 & $71.340,62$ & $3.104 .453,27$ & 49 \\
\hline 1873 & 7.960 & $5.127 .306,53$ & 644 & $73.834,72$ & $3.178 .287,99$ & 62 \\
\hline 1874 & 10.610 & $8.183 .644,60$ & 771 & $86.329,80$ & $3.264 .617,81$ & 40 \\
\hline 1875 & 15.136 & $13.247 .460,58$ & 875 & $95.624,18$ & $3.360 .241,98$ & 25 \\
\hline 1876 & 19.315 & $18.883 .323,93$ & 978 & $152.791,08$ & $3.513 .033,07$ & 19 \\
\hline 1877 & 23.532 & $24.347 .324,79$ & 1.035 & $297.394,05$ & $3.810 .427,12$ & 16 \\
\hline 1878 & 27.711 & $29.728 .141,70$ & 1.073 & $343.448,38$ & $4.153 .875,51$ & 14 \\
\hline 1879 & 31.123 & $34.092 .630,12$ & 1.094 & $295.4+5,80$ & $4.449 .321,30$ & 13 \\
\hline 1880 & 35.950 & $37.724 .662,06$ & 1.049 & 884.411 .00 & $5.333 .732,00$ & 14 \\
\hline 1881 & 39.782 & $39.165 .640,24$ & 985 & $794.966,89$ & $6.128 .699,61$ & 16 \\
\hline 1882 & $38.29 \mathrm{~J}$ & $39.966 .173,86$ & 1.044 & $31.407,81$ & $6.160 .107,42$ & 15 \\
\hline 1883 & 37.441 & $38.404 .591,91$ & 1.026 & $78.508,59$ & $6.238 .616,01$ & 16 \\
\hline 1884 & 37.149 & $41.351 .756,57$ & 1.113 & $519.182,24$ & $6.757 .798,25$ & 16 \\
\hline 1885 & 36.154 & $43.113 .488,12$ & 1.192 & $154.693,46$ & $6.912 .491,71$ & 16 \\
\hline 1886 & 37.866 & $48.820 .564,24$ & 1.289 & $548.909,03$ & $7.461 .400,47$ & 15 \\
\hline 1887 & 39.209 & $52.940 .451,30$ & 1.350 & $302.931,71$ & $7.764 .332,45$ & 15 \\
\hline 1888 & 29.747 & $39.989 .109,71$ & 1.344 & $304.535,97$ & $8.068 .868,42$ & 20 \\
\hline 1889 & 39.268 & $48.122 .878,21$ & 1.225 & $38.756,12$ & $8.107 .624,54$ & 17 \\
\hline 1890 & 41.610 & $48.741 .440,04$ & 1.171 & $96.142,83$ & $8.203 .767,37$ & 17 \\
\hline 1891 & 42.662 & $48.163 .689,29$ & 1.129 & $-113.838,81$ & $8.093 .428,56$ & 17 \\
\hline 1892 & 42.109 & $47.500 .004,60$ & 1.128 & $345.838,27$ & $8.439 .266,83$ & 18 \\
\hline 1893 & 42.578 & $47.795 .285,29$ & 1.123 & 357.680 .28 & $8.796 .947,11$ & 18 \\
\hline 1894 & 43.549 & $48.385 .989,55$ & 1.111 & $600.390,85$ & $9.397 .337,96$ & 19 \\
\hline 1895 & 44.522 & $48.630 .371,94$ & 1.092 & $462.184,41$ & $9.859 .522,37$ & 20 \\
\hline 1896 & 45.778 & $47.836 .706,56$ & 1.045 & $-229.017,18$ & $9.630 .505,19$ & 20 \\
\hline 1897 & 47.663 & $48.848 .212,28$ & 1.025 & $725.662,89$ & $10.356 .168,08$ & 21 \\
\hline 1898 & 48.027 & $45.745 .945,23$ & 953 & $-331.333,36$ & $10.024 .834,72$ & 22 \\
\hline 1899 & 50.595 & $43.993 .804,00$ & 738 & $1.464 .575,26$ & $11.489 .409,98$ & 26 \\
\hline 1900 & 51.074 & $42.629 .157,34$ & 835 & $1.571 .902,61$ & $13.061 .312,59$ & 31 \\
\hline
\end{tabular}

FUENTE: Memorias MPCA de Madrid. Elaboración propia.

anuncios de casas de préstamos y empeños, lo que arroja para estos años una media anual de 520 inserciones ${ }^{\circ}$.

En estas condiciones, el conflicto entre el Monte de Piedad y la Caja de Ahorros por el problema de la colocación de capitales comenzará bien pronto. Creyendo la Caja que las sumas que se recaudarían a través de la misma no

\footnotetext{
- Montero Carnerero (1985).
} 
alcanzarían a cubrir las necesidades del Monte y con el propósito de popularizar y facilitar el acceso a la nueva institución, se acordó elevar la suma semanal que podía colocar cada impositor a 300 reales y a 1.000 la que se podía imponer la primera vez, dejando ilimitado el máximo de cada cuenta personal. Pero la favorable evolución que se observa desde el primer año hace surgir el problema contrario al inicialmente temido y el 8 de mayo de 1841 es necesario reducir a 300 reales la primera imposición y a 100 las sucesivas, estableciendo un límite máximo para cada cuenta de 10.000 reales. Pese a ello, 1841 se cierra ya con 2.001 impositores y casi un millón de pesetas de saldo de ahorro, lo que obliga a nuevas restricciones en 1842: desde el primer domingo de mayo las imposiciones iniciales no podrán ser superiores a 100 reales y las sucesivas no podrán superar los 60 . Algunas ventajas tenía que tener este proceso y Mesonero Romanos señalaría que:

«a beneficio de ellas se fijó verdaderamente el carácter moral del establecimiento, limitando su beneficio a las pequeñas economías de las clases más miserables, se cerró la puerta a los capitales ya formados y que pudieran recibir una aplicación más útil, se estableció el reflujo de imposición y demanda, necesario para equilibrar los ingresos con los medios de empleo y se pudo, en fin, acallar las constantes reclamaciones de la Junta del Monte, que no podía ni quería recibir ya más cantidad».

Pero las nuevas facultades para operaciones pignoraticias de valores, concedidas al Monte de Piedad mediante las Ordenanzas de 23 de noviembre de 1844 restablecerán temporalmente el equilibrio y la Caja irá incrementando su saldo de ahorro en un millón de reales aproximadamente cada año, llegándose a finales de 1847 con 4.109 clientes y un saldo de 2,10 millones de pcsetas. Esta marcha se va a ver sin embargo momentáneamente frenada por los efectos que también en la Caja de Madrid tendrá la crisis de 1848 . La desaparición del dinero metálico y la depreciación de los billetes del Banco de San Fernando provocaron un problema transitorio que tuvo su reflejo en la evolución del saldo de ahorro que en 1848 se redujo en un millón de reales, cerrando con 1,84 millones de pesetas, en tanto que el número de clientes descendió desde 4.109 a 3.335. Para contrarrestar tales efectos, la Junta Directiva acordó que desde primeros de octubre se elevase a 1.000 reales el importe máximo de las primeras imposiciones y a $300 \mathrm{el}$ de las sucesivas, cantidades que fue necesario restringir pronto, "para contener el demasiado ingreso», desapareciendo con ello «todo motivo de duda sobre la estabilidad y risueño porvenir de la institución»”

: Memoria C. A. Madrid, 1848. 
El mejor síntoma de la recuperación es que el año 1849 se va a cerrar con un saldo de ahorro de 2.26 millones de pesetas frente a 1,84 del año anterior y que desde ese mismo año vuelve a ponerse de manifiesto el viejo problema entre el Monte y la Caja por la imposibilidad del primero de invertir los capitales que recibe de la segunda, hasta el punto de que la Junta de la Caja tiene que manifestar su preocupación porque:

«no pueda abrir la mano a las necesidades, a los deseos de tantos laboriosos imponentes como se agolpan cada domingo a sus puertas a depositar el fruto de sus sudores y economía y se vea obligada a restringir aquel movimiento de vital moralidad y de buen orden, disminuyendo continuamente la facultad de imponer hasta las más mínimas sumas, y dejando solo abiertas sus puertas al ochavo del pobre, del artesano, del huérfano y de la viuda».

En 1850 los topes máximos vuelven a situarse en 100 reales para la primera imposición y 60 para las sucesivas y la situación de malestar hace decir a la Junta de la Caja que:

«Este estado de cosas no puede continuar y tiene que hallar solución en uno de dos extremos: o el Monte recibe nueva organización y extiende a mayor esfera el círculo de sus operaciones, o la Caja tiene que cerrar sus puertas a nuevos imponentes y ahogar en su origen tan moral, filantrópica y lisonjera institución.»

Idénticos razonamientos se pueden encontrar en las Memorias de los años 1851 y 1852, año en el que el saldo de ahorro se cierra ya con 3,55 millones de pesetas, pertenecientes a 6.566 clientes. Pero 1853 verá perderse 1.122 clientes (17 por 100) y un saldo de ahorro de casi 600.000 pesetas, cerrándose el ejercicio con 2,99 millones de pesetas. ¿Cómo puede explicarse una reducción tan drástica? La respuesta está en íntima relación con la publicación del Real Decreto de 29 de junio de 1853 mediante el que el Gobierno trataba de dar una regulación uniforme a las Cajas de Ahorros. En el mismo se ordenaba que los fondos que no pudieran ser invertidos por los Montes de Piedad habrían de ser entregados en la Caja de Consignaciones y Depósitos, pero la vinculación que esto representaba con la deuda pública sembró la desconfianza entre los impositores y se produjo una retirada masiva de fondos que obligó al Gobierno a paralizar la reforma. Ello no fue obstáculo para que el ejercicio se cerrara con la disminución ya comentada y que el incremento de los años siguientes sea tan lento que hasta 1856 no se llegara a superar el saldo de ahorro existente antes de la crisis, en 1852. 
Desde 1856 hasta 1862 el crecimiento será constante y bastante uniforme, llegándose el último de ellos a alcanzar los 14.782 clientes y 6,98 millones de pesetas de saldo, el más alto conseguido en esta etapa. Alentada por la demanda de capitales que le efectúa el Monte de Piedad y claramente imbuida la Junta de su misión fomentadora del ahorro, la Caja abrió su primera sucursal en 1861 (calle de la Redondilla) y la segunda en 1862 (Casa Hospicio).

Los años 1863 y 1864 van a venir definidos por una completa estabilidad: casi los mismos impositores que a finales de 1862 y un saldo de ahorro que, con una tendencia levemente decreciente, en realidad prácticamente no se mueve. Esto permite entrever que una nueva situación crítica se está desencadenando, que va a tener ya su reflejo en la Memoria de 1864, donde la Junta comienza a preocuparse por los efectos de la competencia, al observar que:

«el aliciente de mayores utilidades a los capitales ha sido prometido no ya sólo por otras sociedades de índole al parecer análogas, sino por el mismo Gobierno de S. M. que ofreció el 9 por 100 de interés anual a los que llevasen a la Caja de Depósitos sus fondos, aunque fuese en partidas tan pequeñas como las de 500 reales».

A esta situación, que la Caja no puede resolver de inmediato, atada como estaba por la rentabilidad que estatutariamente recibía de las operaciones del Monte de Piedad, en 1865 vendrán a sumarse los efectos de la epidemia de cólera que incrementó las necesidades de efectivo de los clientes más modestos durante los cuatro últimos meses del año. La competencia, incluso la pública, y las enfermedades, hicieron que la Caja perdiera ese año 1.040 clientes y 675.000 pesetas de ahorro, quedando el saldo en 6,19, menos que el registrado en 1860. Como medida de urgencia la Junta acordó pasar la primera imposición a un máximo de 200 reales y las siguientes hasta los 100 reales, aunque esta medida era ya totalmente insuficiente para frenar los efectos de un desastre financiero de gran magnitud como el que se avecinaba: la crisis de 1866, que la Caja de Madrid consiguió plenamente superar. Pese a ello, en 1866 se perdieron 1.439 clientes y 0,39 millones de pesetas de ahorro, sin que en los años siguientes mejorase la situación. En 1867 las pérdidas fueron menores, pero 1868, año al que a la crisis económica mal resuelta se le une la revolución política, verá descender en 1.878 el número de clientes y el saldo de ahorro lo hará en 0,72 millones de pesetas, cerrándose el ejercicio y la etapa aquí analizada con 9.686 clientes y 4,94 millones de pesetas en recursos ajenos, aproximadamente los mismos que en 1858, diez años antes.

Ya en 1867 la Junta trata de combatir esta situación elevando el máximo de las primeras imposiciones hasta los 1.000 reales y a 300 los de las si- 
guientes. Pero si importante era ya la crisis, en 1868 adquirirá una dureza aún mayor, según se refleja en la Memoria de aquel año:

«Sucesos de todos conocidos produjeron la infundada alarma que comenzó a cundir de un modo extraordinario, y en el último período del año, a consecuencia de un terror injustificado, hubo que devolver fuertes sumas, que de otro modo seguirían colocadas con seguridad, y proporcionarían a sus dueños las grandes ventajas que tal vez habrán perdido para siempre.»

La crisis aún no tocado fondo. Lo hará al año siguiente y desde entonces la Caja de Ahorros de Madrid iniciará un lento crecimiento dentro de la agitada situación política y social del Sexenio Revolucionario, sumida en un letargo del que realmente no saldrá hasta 1875 , cuando las nuevas circunstancias políticas hagan renacer la confianza del público en la estabilidad de las instituciones.

\section{La fusión entre la Caja de Aborros y el Monte de Piedad}

La necesidad de una unión entre ambos establecimientos, el Monte y la Caja, va haciéndose sentir de manera cada vez más intensa. Los problemas que periódicamente se le presentan a la Caja relacionados con sus inversiones y con la rentabilidad de su fondo de reserva, la dependencia financiera tan estrecha que existe entre ambas entidades, no ofrece otra solución que la fusión definitiva, terminando con ese peculiar y exclusivo sistema de independencia con que las había dotado el Decreto de 1838. En tal sentido se venía trabajando al menos desde 1863 , cuando a raíz de una Real Orden de 30 de enero se constituyó una comisión mixta encargada de armonizar sus respectivos reglamentos. No se pudo avanzar demasiado y la fusión definitiva se demoraría hasta que de manera forzada fuese promovida por los Gobiernos surgidos de la Revolución de 1868 , que actúan de manera confusa y a veces contradictoria.

El 23 de diciembre de 1868 se promulgó un Decreto suprimiendo las Juntas del Monte de Piedad, la superior y la administrativa, y constituyendo en su lugar un Consejo de Administración. Pero en el mismo no existe representación de la Caja de Ahorros, de cuyos depósitos se nutre el Monte de Piedad para sus operaciones. Con la consiguiente alarma y confusión se reúne el día 30 la Junta Directiva de la Caja que acuerda dirigirse al Ministro de la Gobernación demandando del mismo un desmentido sobre los rumores relativos a la inminente liquidación de la Caja de Ahorros, una declaración 
sobre su solvencia económica y claridad de gestión, una participación institucional de la Caja de Ahorros en el Consejo de Administración del Monte de Piedad, la abstención del Gobierno en cualquier proceso de fusión entre el Monte y la Caja y una declaración final de independencia de la Caja de Ahorros, que considera «perjudicial para ambos establecimientos la refundición de sus administraciones en una sola" ${ }^{8}$.

La resolución ministerial no pudo ser más rápida y el 2 de enero de 1869 se firmó un Decreto por el que, sin perjuicio de resolver definitivamente sobre las cuestiones planteadas, cinco individuos de la Junta de la Caja y por ella misma nombrados, formarían parte en lo sucesivo del Consejo de Administración del Monte de Piedad. Pero el Ministro demora el nombramiento de los elegidos y sin su presencia, el Consejo del Monte aprueba unas nuevas ordenanzas para la entidad. Protesta la Caja y el Ministro paraliza cualquier resolución informándoles que ya estaba decidida la unión entre ambos establecimientos, en contra de los deseos de la Junta de la Caja que, en un ambiente dimisionario, en la sesión celebrada el 22 de marzo deciden continuar en sus puestos para no provocar mayor alarma entre los impositores. El 9 de mayo tiene noticia la Junta de la Caja de que el 22 de abril habían sido aprobadas las Ordenanzas de la nueva entidad y el 11 de mayo, en su última reunión, remiten al Ministro un duro documento de protesta y proclaman su autodisolución. Esta situación fuerza al Ministro de la Gobernación a aprobar el 24 de mayo el Decreto de fusión propiamente dicho, poniendo en vigor las ordenanzas aprobadas el 22 de abril anterior. El 28 de mayo el Director General de Beneficencia ordena al Director de la Caja de Ahorros la entrega al Director del Monte de Piedad, el día 29, de todos los documentos, cauda'es y enseres pertenecientes a la Caja, que termina de esta forma su vida independiente, exactamente treinta años después de iniciarla.

Los efectos económicos de la crisis no podrán ser mayores. Las retiradas de fondos en 1869 ascenderán en la Caja de Ahorros nada menos que a diez millones de reales, dejando los depósitos del establecimiento reducidos a 2,42 millones. Su fondo de reserva, por vez primera, no se incrementa ese año en un solo real y el número de clientes de la Caja, que había llegado a rondar los 15.000 en 1863 , baja de los 10.000 en 1868 y apenas si supera los 5.000 (5.151) en 1869. Se trata de una crisis de carácter profundo, de la que la entidad tardará aún varios años en salir, como más adelante veremos.

De la evolución orgánica e institucional del Monte de Piedad y Caja de Ahorros de Madrid, ya una sola entidad, hasta 1900 muy poco es lo que podemos decir en los límites de este artículo. El Reglamento Orgánico apro-

${ }^{8}$ Actas de la Junta Directiva de la Caja de Ahorros, 30-XII-1868. 
bado por Sagasta como Ministro de la Gobernación el 22 de abril de 1869 era un documento de urgencia con multitud de lagunas e imperfecciones que pronto necesitó ser sustituido, naciendo así los Estatutos de 17 de julio de 1873, aprobados en esta ocasión por el propio Presidente de la Primera República, Francisco $\mathrm{Pi}$ y Margall, quien declara expresamente en la introducción que se trata con ellos de limitar la intervención del Gobierno «cuanto es dable, sin peligro" y de aumentar las competencias del Consejo de Administración. Por lo demás, de lo que se trata es de acomodar las antiguas reglas de gobierno y administración a las nuevas condiciones sociales y en especial al necesario engranaje entre el Monte y la Caja y a su desarrollo tanto presente como futuro.

Los Estatutos de 1873 estuvieron vigentes hasta su sustitución por otros aprobados por Real Decreto de 13 de julio de 1880, con modificaciones meramente operativas, pero que permitieron a la Caja iniciar un amplio proceso de adaptación y reforma que se llevó a cabo entre 1882 y 1883 . A comienzos de la década de los noventa, tras la crisis de 1888 que más adelante estudiaremos, se abrió un nuevo proceso de reforma estatutaria mediante la realización de una amplia encuesta entre Cajas de Ahorros, juristas y empleados de la entidad y a través de la convocatoria de un concurso de memorias sobre la nueva organización, que quedaría finalmente desierto?. El 30 de noviembre de 1892 aprobó el Consejo de Administración unos nuevos Estatutos que no recibieron sin embargo el refrendo gubernamental, con lo que la entidad hubo de seguir rigiéndose durante el resto del siglo por los Estatutos de 1880.

La Presidencia de la Caja fue ocupada desde 1869 por los gobernadores civiles de Madrid (Juan Moreno Benítez, Servando Ruiz Gómez, Ignacio Rojo Arias y Pedro Mata). Pero la entrada en vigor de los Estatutos de 1873 creando la figura del Presidente electivo, permitió que desde entonces se sucedieran en dicho cargo José de Olózaga (1874-1877), el marqués de la Vega de Armijo (1877-1892) y el duque de Veragura (1892 en adelante), dándole al cargo una notable estabilidad.

Tras la fusión del Monte y de la Caja la Dirección de la entidad había recaído en el Capellán de las Descalzas Reales, José Pulido y Espinosa, «por su índole y carácter benéfico y por homenaje a la fundación del Monte de Piedad». No obstante, y pese a esta determinación que se contiene en el artículo 9, el artículo 10 del Reglamento de 1869 prevé que cuando el Consejo lo estime conveniente y lo reclame el servicio, podría proponerse al Gobierno el nombramiento de un Gerente del establecimiento, para ejercer las funciones encomendadas en el Reglamento al Director, conservando siem-

\footnotetext{
"Vellosillo R. Sánchez (1975).
} 
pre el Capellán de las Descalzas el título de Director y las prerrogativas de Consejero. Con esta situación ciertamente atípica para haber sido autorizada por Sagasta y por un gobierno pretendidamente revolucionario, se va a tener que enfrentar el Consejo de Administración desde su toma de posición, una vez conseguida la fusión efectiva. El ejercicio de 1869 fue ciertamente calamitoso y en 1870 las cosas no mejoraron sensiblemente. La entidad estaba muy lejos de recuperar el pulso que había tenido a finales de los cincuenta y comienzos de los sesenta y necesitaba una profunda remodelación. Necesitaba alguien capaz de llevar a cabo una reestructuración que permitiera sacar todo el partido necesario a las nuevas posibilidades que ofrecía la nueva entidad fusionada.

Fue así como el Consejo de Administración se planteó la necesidad de proceder al nombramiento de un jefe administrativo permanente $y$ asiduo, un Gerente según especificaba el Reglamento Orgánico de 1869, que se hiciera cargo de las riendas de la entidad, y fue así como a propuesta del Consejo, el Gobierno se designó mediante Real Orden de 23 de mayo de 1871 para tal puesto al leonés Braulio Antón Ramírez, cuando éste contaba con cuarenta y ocho años de edad, una larga trayectoria en las letras y una sabia experiencia en la administración ${ }^{10}$. Tras tener que superar ciertas dificultades iniciales con el anterior Director, Antón Ramírez fue nombrado DirectorGerente por Decreto de 5 de marzo de 1873, y en el desempeño de dicho puesto estuvo hasta su muerte, el 27 de abril de 1892, dando a la Caja una nueva organización durante su mandato y marcándole un nuevo rumbo y dirección. Tras su muerte fue sustituido en dicho puesto por el Consejero José Alvarez Mariño, bajo cuya dirección la Caja de Madrid se adentraria ya en el siglo $\mathbf{x x}$.

\section{La evolución del saldo de abrorro}

Ya hemos apuntado cómo a la crisis económica que viene soportando la Caja de Madrid al menos desde 1865 , y a los efectos de la crisis política de 1868, se unirán en 1869 las repercusiones de una profunda crisis interna de resultados catastróficos. El saldo de ahorro se reduce en un 50 por 100 , pasando de 4,9 a 2,4 millones de pesetas. Más de 4.500 clientes se espantan y cancelan sus cuentas, dejando las mismas reducidas a poco más de 5.000 . El fondo de reserva no se incrementa en una sola peseta y, desde luego, quienes habían augurado que con la fusión del Monte y de la Caja se resol-

10 Hornillos, López Yepes y Vellosillo (1972). 
verían muchos problemas, debieron llegar a pensar que la reforma se podría haber dejado para mejor coyuntura.

En 1870, sin embargo, las cosas comienzan lentamente a mejorar: la Caja consigue incrementar sus depósitos en 0,6 millones de pesetas y los clientes empiezan tímidamente a recuperar la confianza, registrándose más de 900 nuevos impositores. El ejercicio de 1871, tras la incorporación a la Dirección de Antón Ramírez, se cierra ya con 4,6 millones de pesetas y el de 1872 con 6,3, superándose de nuevo la cota de los 10.000 impositores. Pero 1873 marcará una nueva situación crítica. Razones internas la inician otra vez, cuando el Gobierno estimó la reclamación del Capellán de las Descalzas para ocupar el cargo de Director vitalicio, dejando a la Caja en una situación confusa. La medida iba, además, acompañado de la disolución del Consejo de Administración y su sustitución por una Junta Superior. Ello produjo una alarma entre los clientes que comenzaron nuevamente a retirar sus cuentas. Advertido el Gobierno de los efectos que estaban produciendo sus resoluciones, se avino a dictar un nuevo Decreto que volvía a poner las cosas en su sitio de origen. Era uno de los primeros actos del Gobierno de la Primera República, presidida por Figueras. Pero la rapidez en la resolución no ha sido bastante para frenar una caída de 1,2 millones en el saldo de ahorro y la pérdida de unos 2.300 clientes, que huyen otra vez espantados por los peligros que todo ello pudiera acarrear. Sin embargo, el año 1874 verá mejorar de una manera sensible el panorama, cerrándose con 8,18 millones de pesetas y 10.610 clientes. Y todo parece, en definitiva, indicar que 1875 marcará la fecha de comienzo de una larga etapa de normalidad. Con unos nuevos Estatutos aprobados en 1873, un Reglamento que los desarrolla realizado en 1874, con una recuperación económica en marcha y con la normalización política que representa el regreso de la monarquía borbónica, la Caja se dispondrá a afrontar los nuevos tiempos con la ilusión de abrirse un camino importante en el sistema financiero de la capital de España.

Tras este proceso de normalización, los años siguientes de la historia de la Caja pueden ser calificados como los de auténtico despegue de la entidad, que iniciará entonces un rumbo que la llevará sin sobresaltos hasta 1887 , fecha en la que se consigue el más alto saldo de ahorro de todo el siglo XIX, con 52,9 millones de pesetas, cantidad que la Caja no superará otra vez hasta el ejercicio de 1915. Esta favorable situación hace que la Caja se plantee a partir de 1876 la conveniencia de adquirir una cartera de valores propia, a fin de resolver un problema de inversión que claramente exista, ya que las operaciones del Monte de Piedad no son bastantes para absorber el dinero que los impositores dejan semanalmente en la Caja de Ahorros. Al mismo tiempo se ampliaron los artículos admisibles a empeño. $Y$ es que el problema de la colocación de los recursos de la Caja comienza otra vez a convertirse en una 
preocupación cada vez mayor, que se hará especialmente preocupante en 1879, año en el que se tuvieron que habilitar tres días en semana en vez de uno para facilitar los reintegros, sin ampliar los dedicados a imposiciones, y desde el domingo 16 de noviembre se rebajaron los límites máximos de las imposiciones. Al resultar todo esto insuficiente, a finales de año se autorizó extender hasta veinticuatro meses los préstamos con garantía de valores públicos que, de acuerdo con el Reglamento de 1874, no podían superar los cuatro meses. Medidas igualmente restrictivas fue necesario adoptar en 1880 y más aún en 1881. Desde el 8 de mayo se limitaron nuevamente las imposiciones de 250 a 150 pesetas la primera vez y de 75 a 25 las sucesivas. Para estimular la demanda de préstamos se acordó suprimir el 1 por 100 que se cobraba en las renovaciones de empeños y se redujo la tasa de interés en las pignoraciones de valores desde el 6 al 5 por 100 . Por si ello no fuera suficiente, en mayo se anunció que desde el 1 de enero de 1882 se rebajaría la tasa de interés del ahorro desde el 4 al 3 por 100 .

Estas medidas frenan efectivamente el crecimiento del saldo de ahorro en 1882 y 1883 , pero en 1884 vuelve a producirse ya un importante crecicimiento que se mantendrá hasta 1887 , cerrándose dicho ejercicio con 52,9 millones de pesetas de saldo de ahorro y con 39.209 clientes, sin que la Caja de Madrid se vea especialmente afectada por la crisis de 1882-84.

Pero esta favorable evolución se va a ver bruscamente truncada por una tremenda crisis que azotará a la Caja en el último trimestre de 1888. Durante el primer semestre de aquel año se produjo un importante exceso de tesorería. La alta cotización de los valores impulsó a quienes los tenían pignorados en el Monte a llevar a cabo su desempeño y venta posterior. Las imposiciones seguían progresando, hasta el punto de que el saldo de ahorro llegó hasta los 60 millones de pesetas, llegando a estar más de diez de ellos disponibles sin inversión. El Consejo decidió entonces abrir las posibilidades de pignoración a los valores comerciales $e$ industriales - hasta ahora sólo las tenían los públicos- e invertir en la compra de valores privados una parte del disponible, si la medida inicial no daba el resultado esperado. El público no reaccionó a la oferta de préstamos realizada por la Caja y, en consecuencia, la solución posible era la inversión bursátil. Pero la cartera de valores de la entidad estaba ya bastante nutrida de títulos de la deuda, cuyas cotizaciones, además, eran altas en aquellos momentos, esperándose una caída de las mismas. Fue por ello por lo que, tras analizar las ofertas disponibles, la Caja se decidió por la compra de un paquete de 13.333 obligaciones hipotecarias de los Ferrocarriles del Norte.

La noticia se difundió de manera desfavorable. Se decía que aquellos valores no iban a ser de fácil realización y que los demás capitales estaban afectos a préstamos de largo vencimiento. Una discreta disminución de las 
imposiciones en los primeros días de octubre hizo saltar la alarma y entre los días 12, 13 y 14 del mismo mes se presentaron en la Caja cerca de 9.000 impositores a solicitar el reintegro de sus capitales. En la primera semana la Caja pagó 6,5 millones de pesetas a sus impositores y en el transcurso del mes de octubre la Caja devolvió a 14.000 impositores 24 millones de pesetas. Se remitió entonces al Ministro de la Gobernación un balance al 30 de septiembre pidiéndole llevase a cabo una inspección que comprobase la veracidad de los datos allí contenidos y los hiciera públicos. Además, la Caja aceptó una oferta de compra de las obligaciones hipotecarias, generando con la venta un beneficio de 16.666 pesetas. Pero a finales de noviembre la Caja había sufrido un considerable quebranto. Los 41.211 impositores que había a finales de septiembre se habían reducido a 27.741 , con una pérdida de 13.470 clientes. Los capitales impuestos, que ascendían a finales de septiembre a 58,8 millones, se vieron reducidos en 28 , quedando su saldo en 34,9 y los préstamos con garantía de valores públicos, que ascendían a 46,6 millones de pesetas, descendieron a 28. El ejercicio cerró con 39,9 millones de pesetas.

¿Se trató de una maniobra para reducir a la Caja de Madrid a unos límites puramente asistenciales? Aún es pronto para sacar conclusiones, pero sí es cierto que uno de los problemas de debate en los meses siguientes fue si el Monte de Piedad podía dedicarse a la realización de operaciones financieras -operaciones bancarias como se las denominaba - o debía limitar su actuación a la vertiente puramente social de ayuda al necesitado mediante los préstamos tradicionales. $\mathrm{Y}$ no es menos cierto que en el mes de marzo de 1890 va a tener lugar en el Senado un debate sobre las funciones que debía desempeñar la Caja de Madrid, que requirió la intervención de los Ministros de la Gobernación y de Fomento para defender la posición de la Caja. Y es que, alguno de los intervinientes, considera que la Caja se había apartado del espíritu que animó a sus fundadores y que era urgente encontrar el camino que permitiera volver al mismo, dedicándose exclusivamente a combatir la usura y socorrer a los menesterosos, sin abrogarse la facultad de hacer las operaciones bancarias que venía últimamente realizando.

Los problemas que ha habido que afrontar en 1888 , que han puesto en peligro de desaparición a la propia entidad, hacen que el Consejo se plantee como política de actuación limitar la captación de recursos a las posibilidades reales de inversión, que continúa siendo el auténtico problema de la entidad, teniendo que establecer permanentemente medidas restrictivas al crecimiento del ahorro. En estas condiciones, no es sorprendente ver cómo el saldo de ahorro se estabiliza en 48 millones de pesetas entre 1889 y 1897, descendiendo a 45,7 millones en 1898 , a 43,9 en 1899 y a 42,6 en 1900. Pero se trata de una estabilización primero y de un descenso posterior, que no tienen 
nada que ver con un movimiento crítico, sino el resultado de una actuación reflexiva de ajuste de la entidad a las nuevas directrices de sus Organos Rectores, en los que desde 1892 se ha producido una renovación tanto en la Presidencia como en la Dirección. De haber buscado un cauce de inversión distinto y de habérsele permitido circular por él, la Caja de Madrid podría haberse convertido a finales del siglo xIX en una entidad financiera de primera magnitud a nivel nacional. Se renunció a ello conscientemente, de acuerdo con una política que desde nuestra perspectiva actual no resulta fácil valorar. Lo que sí es cierto es que en 1900, uno de cada 10,5 habitantes de Madrid tenía una cuenta en su Caja de Ahorros y Monte de Piedad, con un saldo medio de 835 pesetas por cuenta.

\section{Las inversiones}

La operatoria básica inicial del Monte de Piedad consiste en la formalización de operaciones de préstamos, dejando los prestatarios en garantía alhajas y ropas. En el cuadro 2 se han recogido los préstamos de este tipo vigentes al terminar el año a partir de 1869 , fecha de la fusión con la Caja de Ahorros. El número de préstamos formalizados a finales de 1869 es de 61.374 y su importe 4,8 millones de pesetas. El dato, que en sí mismo es relevante, adquiere una mayor importancia si tenemos en cuenta que la población de Madrid era entonces de poco más de 350.000 habitantes, lo que representa un empeño por cada 5,7 habitantes de la capital. Dicha cantidad absorbe más del 86 por 100 de los activos de la entidad, pero si tenemos en cuenta la importancia de los recursos propios, comprobaremos lo lejos que estamos de que tales operaciones permitan dar salida a la totalidad de los capitales propios y ajenos de la Caja de Ahorros. Este problema fue constante en la historia de la Caja de Madrid en esta etapa y una fuente permanente de preocupación para sus responsables, que no dejan de introducir medidas encaminadas a fomentar esta operatoria: incentivar a los tasadores para que concedan más valor a los objetos que se empeñan, apertura de sucursales y de despachos auxiliares (llegará a haber 12 en funcionamiento), apertura al público a horarios más favorables, reducción de tasas de interés, supresión de comisiones en las renovaciones, admisión de nuevos objetos a empeño, etc.

Con estas y otras medidas, en 1879 se superaron los 100.000 préstamos vivos (104.215) y su saldo llegó casi hasta los siete millones de pesetas $(6,89)$, pero al año siguiente hay una disminución de unas 10.000 operaciones y el 


\section{CUADRO 2}

Préstamos sobre albajas y ropas y sobre valores, 1869-1900 (En pesetas)

\begin{tabular}{|c|c|c|c|c|c|c|}
\hline \multirow[b]{2}{*}{$A \tilde{n} o s$} & \multicolumn{3}{|c|}{ EMPEÑOS MONTE DE PIEDAD } & \multicolumn{3}{|c|}{ PRESTAMOS SOBRE VALORES } \\
\hline & Número & Saldo & $\begin{array}{l}\text { Importe } \\
\text { por op. }\end{array}$ & Número & Saldo & $\begin{array}{l}\text { Importe } \\
\text { por op. }\end{array}$ \\
\hline $\begin{array}{l}1869 \\
1870 \\
1871 \\
1872 \\
1873 \\
1874 \\
1875 \\
1876 \\
1877 \\
1878 \\
1879 \\
1880 \\
1881 \\
1882 \\
1883 \\
1884 \\
1885 \\
1886 \\
1887 \\
1883 \\
1889 \\
1890 \\
1891 \\
1892 \\
1893 \\
1894 \\
1895 \\
1896 \\
1897 \\
1898 \\
1899 \\
1900\end{array}$ & $\begin{array}{r}61.374 \\
64.516 \\
63.465 \\
65.305 \\
66.825 \\
73.061 \\
76.162 \\
85.982 \\
92.203 \\
97.087 \\
104.215 \\
94.190 \\
88.485 \\
97.210 \\
129.074 \\
130.516 \\
132.408 \\
127.044 \\
121.165 \\
114.359 \\
114.883 \\
116.014 \\
120.242 \\
115.267 \\
114.316 \\
116.233 \\
116.269 \\
110.849 \\
111.192 \\
112.443 \\
115.651 \\
120.136\end{array}$ & $\begin{array}{l}4.861 .023 \\
5.090 .950 \\
4.900 .762 \\
5.332 .682 \\
5.682 .572 \\
6.084 .220 \\
6.113 .965 \\
7.065 .190 \\
6.939 .685 \\
6.861 .470 \\
6.899 .895 \\
6.360 .032 \\
5.867 .141 \\
7.261 .334 \\
9.364 .433 \\
8.762 .656 \\
8.143 .048 \\
7.547 .291 \\
7.401 .018 \\
7.218 .037 \\
7.875 .079 \\
8.052 .720 \\
8.378 .603 \\
8.312 .363 \\
8.216 .471 \\
8.733 .004 \\
8.645 .123 \\
7.223 .452 \\
7.024 .707 \\
6.926 .552 \\
7.214 .852 \\
7.257 .554\end{array}$ & $\begin{array}{l}79 \\
79 \\
77 \\
82 \\
85 \\
83 \\
80 \\
82 \\
75 \\
71 \\
66 \\
68 \\
66 \\
75 \\
73 \\
67 \\
61 \\
59 \\
61 \\
63 \\
69 \\
69 \\
70 \\
72 \\
72 \\
75 \\
74 \\
65 \\
63 \\
62 \\
62 \\
60\end{array}$ & $\begin{array}{l}133 \\
286 \\
522 \\
710 \\
333 \\
726 \\
1.124 \\
1.283 \\
1.552 \\
1.487 \\
1.412 \\
1.322 \\
902 \\
1.047 \\
1.150 \\
1.158 \\
1.413 \\
1.350 \\
1.449 \\
1.005 \\
1.212 \\
1.203 \\
1.066 \\
1.309 \\
1.480 \\
1.401 \\
1.734 \\
1.528 \\
1.495 \\
1.083 \\
993 \\
878\end{array}$ & $\begin{array}{r}319.642 \\
627.542 \\
2.239 .360 \\
3.648 .022 \\
1.414 .977 \\
4.130 .927 \\
7.758 .802 \\
9.600 .965 \\
14.127 .835 \\
17.516 .382 \\
21.445 .795 \\
28.303 .447 \\
29.798 .405 \\
31.314 .946 \\
28.332 .974 \\
27.963 .673 \\
32.700 .305 \\
37.645 .584 \\
44.942 .790 \\
32.372 .441 \\
45.399 .266 \\
41.220 .668 \\
40.369 .903 \\
40.551 .806 \\
41.403 .010 \\
42.027 .256 \\
40.229 .936 \\
41.073 .150 \\
33.512 .214 \\
14.812 .017 \\
15.588 .161 \\
13.711 .156\end{array}$ & $\begin{array}{l}2.403 \\
2.194 \\
4.290 \\
5.138 \\
4.240 \\
5.690 \\
6.903 \\
7.483 \\
9.103 \\
11.780 \\
15.188 \\
21.410 \\
33.036 \\
29.909 \\
24.637 \\
24.148 \\
23.142 \\
27.886 \\
31.016 \\
32.211 \\
37.458 \\
34.265 \\
37.870 \\
30.979 \\
27.975 \\
29.998 \\
23.201 \\
26.880 \\
22.416 \\
13.677 \\
15.698 \\
15.616\end{array}$ \\
\hline Medias & 102.129 & 7.050 .559 & 69 & 1.117 & 22.265 .161 & 19.933 \\
\hline
\end{tabular}

Fuenre: Memorias MPCA de Madrid. Elaboración propia. 
saldo total ha descendido hasta los 6,36 millones de pesetas, lo que es considerado como lamentable por los directivos del Monte de Piedad. Pero ¿podían las cosas ser de otra forma? En 1880 la población de Madrid era de 398.000 habitantes y existía, por consiguiente, al 31 de diciembre un empeño en el Monte de Piedad por cada 4,22 personas, más de uno por familia; y si comparamos la cifra de habitantes con el número de operaciones realizadas en el año, 163.607 empeños, observamos que se ha producido un empeño por cada 2,4 habitantes. So pena que una misma familia acudiera reiteradamente al Monte de Piedad a empeñar cuanto poseía, era francamente difícil incrementar la cuota de mercado dado el tamaño de la ciudad de Madrid.

Pese a ello los intentos por incrementar la operatoria no cesan. Se llegó a estudiar la posibilidad de realizar empeños a domicilio. Con ello se alcanzó en 1885 un máximo de préstamos vivos para toda esta etapa, 132.408, si bien su importe medio ha descendido del entorno de las 70 pesetas por operación, al entorno de las 60 , y lo que había sido la principal actividad inversora de los caudales de la Caja, cada vez se manifiesta más insuficiente para hacer frente a las necesidades inversoras de la entidad. $\mathrm{Al}$ acabar el siglo, en 1900, el Monte de Piedad registra 187.669 operaciones de préstamo, de las que 120.136 permanecían activas al terminar el año, con un saldo total de 7,25 millones de pesetas, que representaban el 12,8 por 100 de los activos de la Caja de Ahorros. Hay que hacer notar, nuevamente, lo que ello significa para una población de 540.000 personas; el Monte de Piedad ha realizado en el año un empeño por cada 2,8 habitantes de Madrid y a finales de año tiene un préstamo formalizado por cada 4,5 habitantes de la ciudad, lo que estadísticamente representa, al menos, un préstamo por familia.

La media por operación formalizada se sitúa en este período en 69 pesetas, con un máximo de 85 para 1873 y un mínimo de 59 pesetas para 1886, con una evolución anual que ha quedado también reflejada en el cuadro 2 y en el que se detecta una tendencia regresiva en los años finales del sig’o. Así, si en 1869 la media por operación asciende a 79 pesetas, en 1900 esta media se situará únicamente en 60 . En medio hay treinta y dos años de actividad. El saldo total ha pasado en esos años de 4,8 millones de pesetas a 7,2 y de los 32 años del período, en la mitad de ellos el saldo se ha incrementado y en la otra mitad ha descendido, lo que justifica el escaso crecimiento total registrado.

La distribución de la operatoria entre alhajas y ropas es favorable a las primeras con un 87 por 100 del total de los préstamos concedidos, como promedio, frente a un 13 por 100 que representan los préstamos sobre ropas. Naturalmente que en cuanto a número de operaciones de cada una de estas dos modalidades esta relación es mucho más equilibrada, aunque siempre favorable a los empeños sobre alhajas. La media por operación en los prés- 
tamos sobre ropas es de 22 pesetas para todo el período, que se elevan hasta las 98 pesetas en las operaciones sobre alhajas. En todo caso, la escasa importancia de unos y otros permite calificar esta operatoria como de absoluta subsistencia.

No sucede lo mismo con los préstamos con garantía de valores, cuya evolución se contiene en el mismo cuadro 2. El Reglamento del Monte de Piedad de 1844 le había autorizado para conceder préstamos con garantía pignoraticia de valores públicos, siempre que la demanda de operaciones habituales de empeño no fuese suficiente para absorber el dinero depositado en la Caja de Ahorros. Por sorprendente que parezca, esta facultad no se concedió a la Caja de Ahorros, que aportaba los fondos, sino al Monte de Piedad. Hubo años, como 1863, en que los beneficios del Monte por dichas operaciones ascendieron a un millón y medio de reales, con los que no solamente atendió todos sus gastos de funcionamiento, sino que pudo incrementar su propio patrimonio, que en el momento de la fusión con la Caja ascendía a más de dos millones de pesetas.

Sin embargo, el Reglamento de 1869 limitará mucho estas operaciones al establecer un máximo para cada una de ellas de 2.000 reales. Pero ésta fue una situación transitoria. En 1870 el Consejo obtuvo autorización para elevar este máximo hasta 10.000 reales y en 1871 hasta 50.000. En 1872 la Caja obtuvo para estas operaciones una facultad ilimitada y la libertad de determinar ella misma, no el Gobierno, qué tipos de valores habrían de admitirse a pignoración. Los resultados no se hacen esperar y en unos pocos años el número de operaciones pasa de poco más de 100 a más de $1.000 \mathrm{y}$, lo que es más importante, su saldo y su importe medio crecen de manera muy considerable. $Y$ es evidente que hay una política consciente de fomento de esta operatoria como mejor solución al problema de las inversiones. La tasa de interés es del 5 por 100 anual, frente al 6 por 100 que se cobraba en los préstamos sobre alhajas y ropas. Pero es que, desde 1878 , la Caja corre con los gastos de corretaje de los agentes interventores, comienza a computar los intereses por días y eleva el importe a conceder en préstamo hasta las tres cuartas partes del valor de cotización de los valores pignorados. En 1885 la tasa de interés se bajará al 4,5 por 100 y en 1892 al 4 por 100 anual.

$\mathrm{El}$ número de operaciones sobre valores alcanzará su techo pronto, a finales de la década de los setenta, situándose entonces entre las 1.400 y las 1.500 operaciones vivas al finalizar cada año. Desde 1881 este número desciende para situarse en torno a las 1.000 operaciones para volver a crecer desde 1892 hasta 1897, iniciando un nuevo declive a partir de 1898. Por lo que se refiere a su saldo, crecerá de una manera estable hasta 1887 , estabilizándose después hasta 1896 para decrecer desde dicho año. El importe que como promedio tuvo la Caja de Madrid invertido en estas operaciones fue 
de 22,26 millones de pesetas, que para un número medio anual de 1.117 operaciones arrojan un saldo medio por operación de 19.993 pesetas. $Y$ si el porcentaje que representan los préstamos sobre alhajas y ropas sobre el total de los activos no parará de descender, estabilizándose entre el 12 y el 14 por 100 de los mismos desde 1885 , el porcentaje que los préstamos sobre valores públicos representa sobre la totalidad de los activos, que se recoge en el cuadro 4 , crecerá permanentemente hasta situarse en torno al 70 por 100 de los activos de la entidad.

La importancia de estas operaciones queda simplemente reflejada en el dato de que, para el conjunto del período aquí analizado, representaron un promedio anual de un 51,6 por 100 de los activos totales. Por otra parte, el importe medio por operación, 19.993 pesetas, está muy lejos de aquellas 69 pesetas en que se situaba el promedio de las operaciones realizadas sobre alhajas y ropas alcanzándose, por ejemplo en 1891, las 37.870 pesetas de importe medio por cada una de las operaciones vigentes al 31 de diciembre de aquel año. Así las cosas, es indudable que los préstamos sobre valores públicos fueron la principal actividad de la Caja en materia de inversiones en el conjunto de la etapa que analizamos en este trabajo. Y ni la garantía ni el importe permiten deducir que la Caja está realizando con esta operatoria actividad asistencial, sino pura y simplemente financiera.

$Y$ por lo que se refiere a las inversiones directas en valores, cuyo saldo aparece en el cuadro 3, la primera vez que con cierta importancia aparecen en los balances de la Caja de Madrid será en 1875, cuando se compran billetes hipotecarios del Banco de España que aparecen contabilizados por $0,88 \mathrm{mi}$ llones de pesetas. A partir de 1876 la presencia de valores en el balance va a crecer en importancia, ocupando casi siempre, como puede verse en el cuadro 4, el segundo lugar, detrás de los préstamos sobre valores pero delante de la actividad que pudiéramos considerar más típica, los empeños de alhajas y ropas. Los valores que sucesivamente van entrando en el balance son títulos de gran seguridad y razonable rentabilidad para el momento: Obligaciones del Tesoro al 5 por 100, Obligaciones del Tesoro sobre la renta de las aduanas, Deuda Amortizable al 2 por 100, Deuda Perpetua al 3 por 100, Obligaciones de Ferrocarriles, Acciones del Banco de España y Deuda Amortizable al 4 por 100. Pero lo cierto es que la presencia de la Caja en el mercado de valores es una presencia forzada por la falta de posibilidades de inversión en sus actividades más típicas y es frecuente encontrar en las Memorias de la entidad justificaciones de por qué se recurre a este tipo de inversión.

$\mathrm{Y}$ es que no podemos olvidar la relación entre inversión bursátil y especulación, el amasamiento de grandes fortunas y la consumación de grandes ruinas. Esta sensibilidad popular es la que actuará en 1888 cuando a raíz de una compra de obligaciones de los Ferrocarriles del Norte se difundieron una 


\section{CUADRO 3}

Valores, inmuebles y tesorería, 1869-1900

(En pesetas)

\begin{tabular}{|c|c|c|c|c|}
\hline & $A \tilde{n} o s$ & Valores & Inmovilizado & Disponible \\
\hline $\begin{array}{ll}1869 & \ldots \\
1870 & \ldots \\
1871 & \ldots \\
1872 & \ldots \\
1873 & \ldots \\
1874 & \ldots \\
1875 & \ldots \\
1876 & \ldots \\
1877 & \ldots \\
1878 & \ldots \\
1879 & \ldots \\
1880 & \ldots \\
1881 & \ldots \\
1882 & \ldots \\
1883 & \ldots \\
1884 & \ldots \\
1885 & \ldots \\
1886 & \ldots \\
1887 & \ldots \\
1888 & \ldots \\
1889 & \ldots \\
1890 & \ldots \\
1891 & \ldots \\
1892 & \ldots \\
1893 & \ldots \\
1894 & \ldots \\
1895 & \ldots \\
1896 & \ldots \\
1897 & \ldots \\
1898 & \ldots \\
1899 & \ldots \\
1900 & \ldots\end{array}$ & 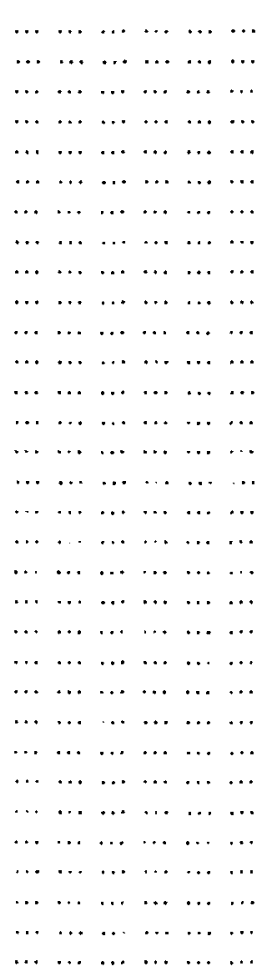 & $\begin{array}{r}45.061 \\
51.192 \\
44.487 \\
24.241 \\
34.662 \\
886.005 \\
3.479 .769 \\
5.251 .821 \\
6.605 .716 \\
6.303 .888 \\
4.372 .835 \\
4.820 .086 \\
4.138 .234 \\
3.801 .647 \\
4.052 .508 \\
3.958 .911 \\
4.287 .241 \\
4.441 .019 \\
20.850 \\
20.575 \\
4.475 .050 \\
4.074 .100 \\
3.898 .700 \\
3.849 .000 \\
4.243 .980 \\
6.845 .150 \\
6.733 .425 \\
15.256 .871 \\
26.196 .245 \\
27.478 .890 \\
28.214 .665\end{array}$ & $\begin{array}{r}235.871 \\
334.653 \\
455.511 \\
777.775 \\
947.348 \\
1.247 .264 \\
1.275 .984 \\
1.278 .797 \\
1.278 .847 \\
1.278 .847 \\
1.329 .469 \\
2.282 .709 \\
2.349 .281 \\
2.541 .469 \\
2.895 .185 \\
3.255 .855 \\
3.602 .698 \\
3.600 .509 \\
3.569 .171 \\
3.525 .209 \\
3.481 .575 \\
3.446 .039 \\
3.412 .190 \\
3.093 .118 \\
2.784 .729 \\
2.780 .925 \\
2.777 .121 \\
2.732 .900 \\
2.732 .900 \\
2.493 .597 \\
2.423 .597\end{array}$ & $\begin{array}{r}314.500 \\
798.033 \\
411.969 \\
257.178 \\
623.015 \\
520.698 \\
1.056 .244 \\
1.407 .322 \\
985.631 \\
2.101 .699 \\
3.353 .021 \\
3.410 .817 \\
3.055 .819 \\
1.713 .613 \\
1.229 .655 \\
4.758 .072 \\
2.713 .008 \\
4.027 .902 \\
1.678 .225 \\
6.289 .834 \\
1.259 .028 \\
1.196 .938 \\
1.471 .863 \\
1.146 .362 \\
1.380 .161 \\
1.512 .369 \\
1.366 .824 \\
1.115 .742 \\
2.124 .074 \\
6.620 .636 \\
4.464 .452 \\
5.047 .785\end{array}$ \\
\hline
\end{tabular}

FuENTE: Memorias MPCA de Madrid. Elaboración propia.

serie de comentarios que llevaron a la Caja de Madrid a la crisis más grande por la que tuvo que atravesar a lo largo de todo el siglo xix y que pudo haberle costado su propia existencia, como vimos en un punto anterior. Para hacer frente a aquella crisis la Caja vendió toda su cartera, pero en 1890 , con la vuelta a la normalidad, es necesario volver a plantearse esta inversión, adquiriendo poco más de 4,4 millones de pesetas de Deuda Amortizable al 4 


\section{CUADRO 4}

Distribución porcentual de los activos

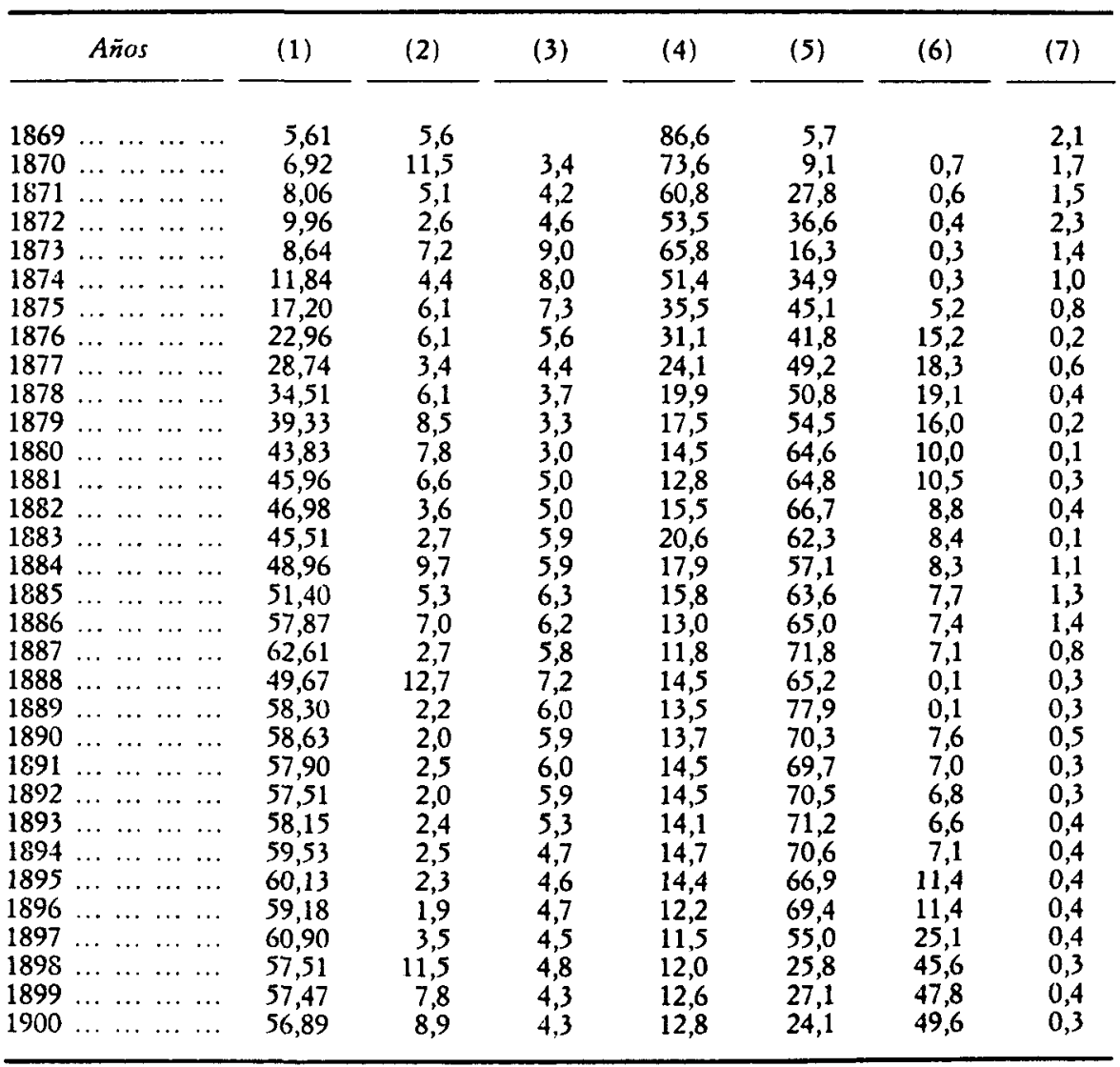

(1) Activos totales (en millones de pesetas).

(2) Disponible.

(3) Inmovilizado.

(4) Préstamos sobre alhajas/ropas.

(5) Préstamos sobre valores públicos.

(6) Valores.

(7) Otros activos.

FuenTE: Memorias MPCA de Madrid. Elaboración propia. 
por 100 , que se va a mantener en la cartera, casi en exclusiva por razones de prudencia, hasta 1896, si bien en los dos últimos años se ha incrementado su importe en 2,5 millones de pesetas.

Desde 1897 se produce una caída en la demanda de préstamos con garantía de valores que se acentúa en 1898. La crisis de aquel año, por una parte, la subida de las cotizaciones de los valores públicos, la elevación del precio del timbre en las pólizas y la reducción de su validez a la mitad del tiempo, justifican una contención a la que la Caja ha de hacer frente acudiendo a realizar su disponible al mercado de valores. Así, los tres últimos años del siglo verán incrementarse el saldo por la compra de Obligaciones del Tesoro, Obligaciones sobre la Renta de Aduanas y Deuda Amortizable. Con ello, la cartera de valores, que había representado un prudente porcentaje, sobre los activos, comprendido entre el 7 y el 10 por 100 , pasará al 25 por 100 en 1897 , al 45 en 1898 y casi alcanzará el 50 por 100 de los activos, con 28,2 millones de pesetas, en 1900 .

Finalmente, en los cuadros 3 y 4 se ha recogido la información absoluta y porcentual del inmovilizado y del disponible, cuya importancia dentro de los activos es muy secundaria si la comparamos con las restantes magnitudes ya comentadas.

\section{Los recursos propios}

El primer reglamento de la Caja, aprobado por Real Orden de 17 de julio de 1839 , determinaba en su artículo tercero que la diferencia entre el 5 por 100 que el Monte pagaba a la Caja y el 4 que ésta abonaba a sus clientes, se destinaría a abonar los gastos de la Caja y a constituir un fondo de reserva para imprevistos. En el cuadro 1 se recoge la cuenta anual de resultados de la Caja de Madrid y la evolución de su fondo de reserva. La acumulación año tras año de las cantidades que se obtienen como beneficio anual es lo que constituye el fondo de reserva y con la estructura de inversiones tan restringida con que surge la Caja de Madrid, todo su dinero ha de entregárselo al Monte de Piedad, es difícil que ésta pudiera tener pérdidas, salvo que se diera una situación desastrosa en el Monte de Piedad o que la Junta de la Caja de Ahorros hubiera seguido una política de gasto dilapidatoria. No sucedió ni una cosa ni otra. El Monte abonó sus intereses a la Caja y ésta consiguió un beneficio diferencial adecuado a las circunstancias en que se mueve. $\mathrm{Y}$ esta situación hace que, al no existir nunca pérdidas, el fondo de reserva experimente una evolución siempre positiva y que partiendo de las 3.375 pesetas con que se constituye en 1841 , como resultado de la gestión del año anterior y de los meses en los que se operó en 1839, alcance en 
1868 la importante suma de 710.661 pesetas, que representaba un coeficiente sobre los recursos ajenos nada menos que de un 14,4 por 100 y daba a la Caja una situación de sanidad financiera espléndida.

Cuando el 29 de mayo de 1869 se produce la fusión entre el Monte de Piedad y la Caja de Ahorros de Madrid, se realiza la integración de sus respectivos fondos de reserva. Ascendía entonces el del Monte de Piedad a 2.021.662,67 pesetas y el de la Caja de Ahorros a 729.419,44 pesetas, con lo que el nuevo fondo resultante ascenderá a $2.751 .082,17$ pesetas que, con la acumulación de los beneficios durante el resto del ejercicio de 1869 , permiten cerrar este año con 2,85 millones de pesetas, equivalentes a un 118 por 100 del saldo de depósitos de la Caja de Ahorros, en crisis, por cierto, aquel año, según vimos.

El incremento de la cifra absoluta de beneficios que tiene lugar en 1869 , pese a esta situación crítica, tiene su fundamento en la fusión que se acaba de producir con el Monte de Piedad, de manera que lo que este dato refleja es el resultado de la operatoria conjunta de las que hasta ahora eran dos entidades.

En 1871 la cuenta de resultados ofrece una importante reducción de más del 45 por 100 , motivada por un aumento de los gastos (24 por 100) muy superior al de los ingresos (5 por 100). El incremento de los saldos de ahorro ese año en un 47 por 100 unido a una contención de los empeños y a las dificultades reglamentarias para canalizar los fondos disponibles hacia otras inversiones justifican tal situación. Sin embargo, y por la evolución que observamos en los años siguientes, ése es el ritmo al que se va a ajustar la cuenta de resultados que desde entonces va a desarrollarse de una manera muy homogénea. $Y$ este coeficiente de garantía, medido como la relación existente entre los recursos propios o fondos de reserva y los recursos ajenos o depósitos de clientes, va a estar casi permanentemente en descenso hasta 1879 y a medida que aumentan los saldos de ahorro el coeficiente abandona sus atípicas posiciones iniciales que hicieron que hasta 1873 estuviera situado por encima del 50 por 100 .

La evolución de la cuenta de resultados no va a tener otras incidencias destacables hasta 1880 . Pero el criterio que aquel año se adopta, de valorar anualmente en balance la cartera de valores de acuerdo con la cotización de cada uno de los títulos y registrar como pérdida o beneficio la diferencia, hará que desde entonces el beneficio anual se mueva de forma heterogénea $y$ que no resulte sencillo deducir de este dato la calidad de la gestión realizada. Aun así, lo que sí se puede afirmar es que los recursos propios de la Caja pasarán de 2,7 millones de pesetas en 1868 a 13 en 1900 , lo que representa un incremento total del 375 por 100 para este período.

El coeficiente de garantía del Monte de Piedad y Caja de Ahorros de 
Madrid a lo largo de todo el último tercio del siglo xIX es realmente extraordinario. Hay un año, 1869, en que se sitúa en el 118 por 100 , lo que quiere decir que hay más recursos propios que ajenos. Durante cinco años, 1869 . 1873, estuvo por encima del 50 por 100 . El año en que más bajo estuvo fue en 1879, pero aun así se situó en el 13 por 100 . Y la tónica general durante los últimos años del siglo es la de mantenerse permanentemente entre el 15 y el 20 por 100 , lo que quiere decir que los recursos propios están creciendo al mismo ritmo que los ajenos. Una mayor garantía para la clientela y unos mejores resultados serían difíciles de encontrar.

$\mathrm{Y}$ todo ello, sin que los directivos de la Caja se planteen como objetivo de su actividad la cuenta de resultados en sí misma. De los propósitos que les animan baste citar esta referencia procedente de la Memoria de 1877:

«La preocupación, siquiera momentánea, con los cálculos sobre las utilidades nos llevaría fácilmente a las preocupaciones y cálculos de los financieros, olvidando la índole compleja, fines y servicios que aquí predominan: la utilidad es siempre verdaderamente importante, pero aquí debe mirarse como de un interés secundario. El Establecimiento cumpliría dignamente su misión... sólo con llenar el objeto para que se creó y con no debilitar en nada su propio caudal.»

\section{BIBLIOGRAFIA}

González Moreno, José Manuel (1983): Naturaleza y régimen juridico de las Cajas de Ahorros, Madrid.

Hornillos, Carlos; López Yepes, José, y Vellosilloo, Faustino (1972): «Las Cajas de Ahorro en el siglo xix. La obra de Braulio Antón Ramírez (1823-1892)», Boletín de Documentación del Fondo para la Investigación Económica y Social de la CECA, vol. IV, fascículos $10^{\circ}, 20^{\circ}$ y $3 .^{\circ}$.

López Yepes, José (1971): Historia de los Montes de Piedad en España. El Monte de Piedad de Madrid en el siglo XVIII, Madrid, CECA, 2 tomos.

- (1973): Historia urgente de Cajas de Aborros y Montes de Piedad en España, Madrid, CECA.

Martí-Retortillo Baquer, Sebastián (1975): Crédito, Banca y Cajas de Aborros. Aspectos juridico-administrativos, Madrid, Tecnos.

Montero Carnerero, Manuel (1983): «Bases documentales para la investigación del préstamo y la usura en la sociedad del siglo XIX», Monografías, núm. 10, CECA, diciembre.

- (1985): «El préstamo en el Diario Óficial de Avisos de Madrid (1856-1873). Estudio estadístico y análisis de contenido", Monografías, núm. 11, CECA, febrero.

Pereda, Vicente de (1946): Libro de la Caja de Aborros y Monte de Piedad de Madrid, Bilbao. 
Titos Martínez, Manuel (1978): Crédito y Aborro en Granada en el siglo XIX, Granada, Banco de Granada, 2 tomos, I.

Vellosillo R. SánChez, Faustino (1975): «La actuación de la Comisión de Reformas de la Caja de Ahorros y Monte de Piedad de Madrid (1889-1893)», en Estudios de Historic de Cajas de Aborros y Montes de Piedad, Madrid, CECA, pp. 23-38. 